\section{Petunjuk Dasar Pemeriksaan Bangunan Existing Metode Non-Destructive Test: Studi Kasus Bangunan Industrial Struktur Baja}

\section{Usman Wijaya}

Dosen Teknik Sipil, Universitas Kristen Krida Wacana, Jl. Tanjung Duren Raya No.4, Jakarta 11470. Direktur, PT Deltakoni, Metland Tambun A2 No. 41, Bekasi 17510

$\triangle \quad$ usman.wijaya@ukrida.ac.id
Beberapa peraturan di negara maju mensyaratkan perlunya pemeriksaan bangunan existing tiap kali adanya update peraturan baru. Di-Indonesia sendiri belum ada peraturan yang mengatur perlunya pemeriksaan bangunan setiap ada update peraturan, namun belakangan Kementerian Pekerjaan Umum dan Perumahan Rakyat (PUPR) menginstruksikan untuk menerbitkan sertifikat laik fungsi bangunan (SLF) setiap 5 tahun dimana salah satu persyaratannya mensyaratkan pemeriksaan bangunan existing. Umumnya alasan dilakukan pemeriksaan bangunan existing karena adanya update peraturan, umur bangunan, perubahan fungsi bangunan, dan kerusakan akibat gempa. Pada Studi kasus ini bangunan industri dibangun tahun 1990, akibat update peraturan dan umur bangunan, maka bangunan akan di periksa dengan metode non-destructive test (NDT) menggunakan Brinell Hardness Test dan Ultrasonic Pulse Velocity (UPV) Test. Metode NDT dipilih karena tidak mengganggu operasional bangunan. Dari hasil pengujian NDT dan analisis struktur berdasarkan data aktual dilapangan menunjukan beberapa struktur tidak memenuhi kriteria desain dengan peraturan terbaru AISC 360-16 dan perlu retrofit untuk kondisi yang tidak memenuhi kriteria desain.

Kata kunci : Assessment, NDT Test, ASD, LRFD

Diajukan: 13 September 2019

Direvisi: 14 September 2019

Diterima: 25 September 2019

Dipublikasikan online:1 Oktober 2019

\section{Pendahuluan}

Dewasa ini proyek pembangunan masif dilakukan diseluruh pelosok nusantara. Pembangunan dari bangunan gedung bertingkat seperti mall, hotel, apartemen gedung perkantoran, sampai bangunan industri banyak dilakukan. Dengan kondisi perekonomian yang meningkat sejalan dengan kegiatan membangun negeri, kebutuhan akan suatu hunian sebagai pusat aktivitas, pusat bisnis dan pusat pemerintahan tidak dapat dihindarkan lagi. Namun dalam beberapa kondisi kegiatan membangun tersebut tidak dapat dilakukan dengan beberapa pertimbangan, diantaranya bangunan warisan cagar budaya, bangunan bersejarah, bangunan yang penting yang masih digunakan, yang akan menggangu kegiatan sehari-hari apabila dilakukan kegiatan konstruksi. Dengan kebutuhan akan perubahan fungsi bangunan akibat perekonomian meningkat namun bangunan existing tidak boleh berhenti digunakan akibat kegiatan konstruksi yang masif, maka pemeriksaan bangunan dibutuhkan. Pemeriksaan bangunan bertujuan untuk melakukan pemeriksaan secara menyeluruh bangunan existing apakah masih memenuhi kriteria desain apabila dilakukan sebagian perubahan, misalnya perubahan fungsi ruangan, penambahan beban lain-lain.

Jika merujuk pada konstruksi baja negara maju seperti Amerika Serikat, secara teratur mereka memperbarui teknologi perencanaan yang dikukung dengan adanya riset pada bagian tersebut. Sejak ASD edisi pertama keluar pada tahun 1927, America Institute of Steel Construkction terus melakukan upaya peningkatan mutu perencanaan sampai dengan bulan juni 2019 lalu telah terbit AISC 360-16. Dari metode yang paling popular dikalangan praktisi aitu metode ASD hingga metode yang relative baru ditemukan yaitu LRFD yang mampu untuk memberikan keamanan yang lebih andal dengan cara yang efisien sehingga disebut sebagai cara batas. Beberapa kemungkinan terkait dengan bangunan dapat di perhitungan pada metode LRFD seperti penampang plastis (Mp) atau juga secara kekuatan material yang ada pada sambungan yang memperngaruhi daktilitas struktur tersebut. Dapat dikatakan bahwa metode perhitungan secara LRFD lebih mendekati dengan kondisi aktial dari profil yang ditinjau tersebut yang pada metode ASD hanya dapat mencakup tegangan leleh dan tegangan kritis saja. (Dewobroto, 2015a).

Untuk mendapatkan parameter penunjang dalam melakukan perhitungan kapasitas perlu untuk dilakukan pemeriksaan terhadap mutu elemen structural yang ada. Dalam beton untuk mendapatkan mutu beton aktual dapat dilakukan dengan cara test destruktif yang mempunyai sifat merusak terhadap bagian yang ingin diperiksa. Sebagai alternative dapat juga dilakukan test non-destruktif yang memiliki sifat tidak merusak (Jayakumar dan Thavasimuthu, 2007). 
Pada penelitian ini, studi kasus kebutuhan pemeriksaan bangunan existing lebih disebabkan karena umur bangunan dan update peraturan terbaru, sehingga analisis struktur bangunan industri yang telah dibangun pada 20 tahun silam dengan menggunakan beberapa metode disain yang ada perlu di kaji ulang dengan peraturan yang terbaru. Bangunan yang akan dikaji ulang berlokasi di daerah Tangerang, dengan jumlah lantai satu dan memiliki Panjang 42 meter, lebar 46-meter dan tinggi 8.8 meter (Gambar 1). Struktur existing didesain dengan sistem rangka momen yang difungsikan sebagai bangunan industri. Beban imposed $1000 \mathrm{~kg} / \mathrm{m} 2$ pada bagian lantai dasar dan $400 \mathrm{~kg} / \mathrm{m} 2$ pada bagian lantai mezzanine. Data mutu baja akan didapatkan dengan Brinell Test, data mutu beton pedestal beton akan didapatkan melalui UPV test.

\section{Metode}

\section{Metode Kerja Ultrasonic Pulse Velocity (UPV)}

Direct transmission, semi-direct transmission dan indirect transmission adalah tiga metode pengujian ultrasonic pulse velocity seperti terlihat pada Gambar 2 . Metode direct transmission direkomendasikan untuk dilakukan dalam menambil data karena dapat mengambilan data dengan keandalan yang baik. Tetapi metode ini sering terkendala dengan praktek dilapangan. Jika untuk melakukan direct transmission tidak memungkin kan untuk dilakukan maka bisa digunaka metode lainnya seperti semi-direct transmission dan indirect transmission. Metode indirect transmission meiliki hasil yang kurang andal sehingga dalam pembacaanya perlu untuk diberikan koefisien reduksi. Dalam setiap pengujian permukaan area yang ingin diuji dioleskan gel ultrasonic terlebih dahulu. Tipe dan ukuran aggregate, usia beton, kelembaban udara pada proses perawatan dapat memberikan pengaruh pada proses pengujian UPV (Sbartaï dkk, 2012).

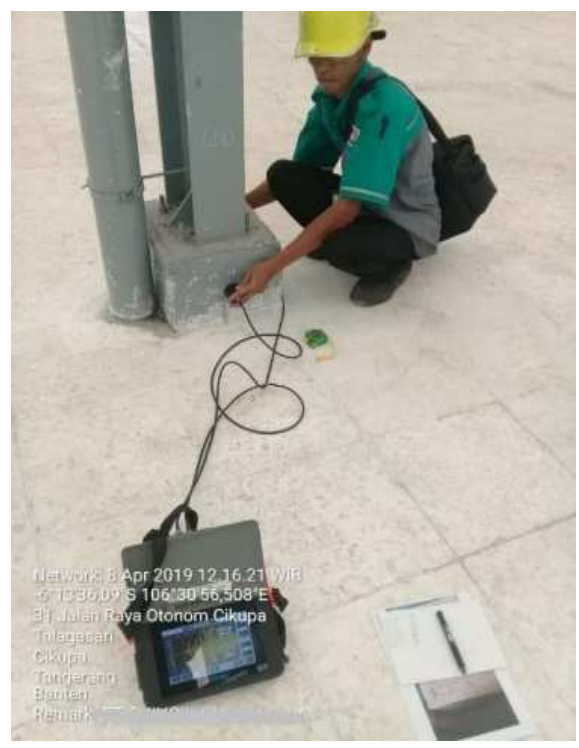

Gambar 1. Pekerjaan UPV test

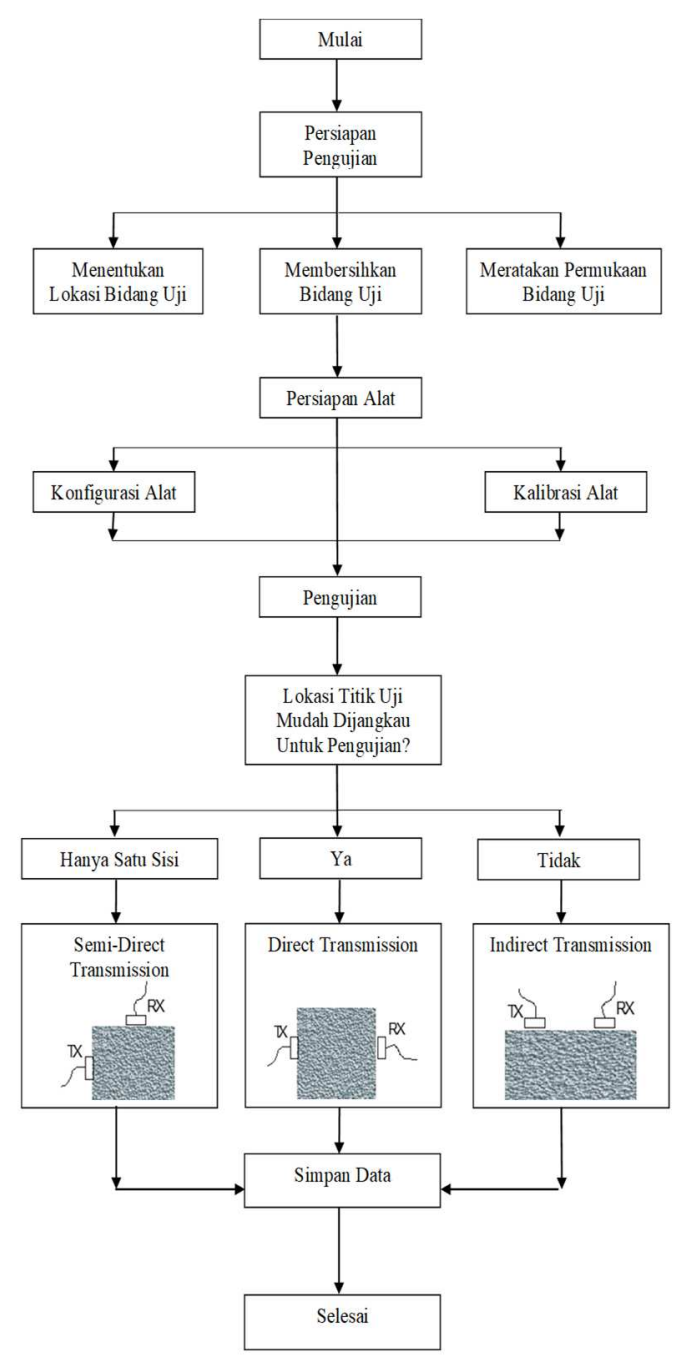

Gambar 2. Alur Kerja UPV Test

\section{Metode Brinell Hardness Hardness Test}

Brinell hardness test ditemukan oleh J.A Brinell pada tahun 1900 dan kemudian disusun kembali pada tahun 1987 oleh dieter. Metode ini merupakan upaya untuk mengetahui sifat dari suatu material yang disukai karena caranya yang sederhana dan tidak merusak.

Bola besi berdiameter $10 \mathrm{~mm}, 5 \mathrm{~mm}, 2.5 \mathrm{~mm}$ dan 1 $\mathrm{mm}$ digunakan sebagain indenter pada metode ini sesuai dengan standar internasional yang berlaku. Bola besi tersebut kemudian diberikan gaya tekan $1-3000$ kgf yang kemudian dibagi dengan luas permukaan indentasi residu pada specimen tersebut untuk mendapatkan hasil test. Terori yang digunakan dalam menghitung luas permukaan indentasi bola residu yaitu dengan rata rata dari kedua diagonal yang tegak lurus ( $d_{1}$ dan $d_{2}$ ) (Gambar 3 ).

Nilai Brinell Hardness (HBW) dapat di rumuskan sebagai berikut:

$$
\begin{aligned}
& H B W=0.102 \times \frac{2 F}{\pi \times D^{2} \times\left(1-\sqrt{1-\frac{d^{2}}{D^{2}}}\right.} \\
& d=\frac{d_{1}+d_{2}}{2}
\end{aligned}
$$


Nilai rata rata terhadap diameter indentasi ditampilkan dengan nilai $d$ yang pada prakteknya perhitnugan tersebut tidak digunakan pada setiap pengujian. Nilai dari pengujian Brinell Harness dapat didapatkan melalui software yang telah deprogram khusus ataupun dibaca melalu tabel yang sudah tersedia. . Pengujian Brinell Hardness Test terlihat pada Gambar 4.

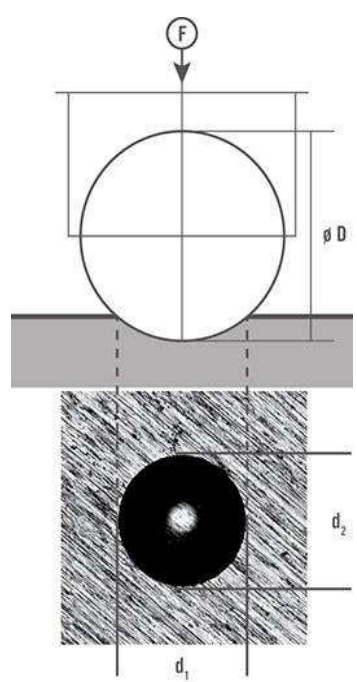

Gambar 3. Brinell Hardness Test

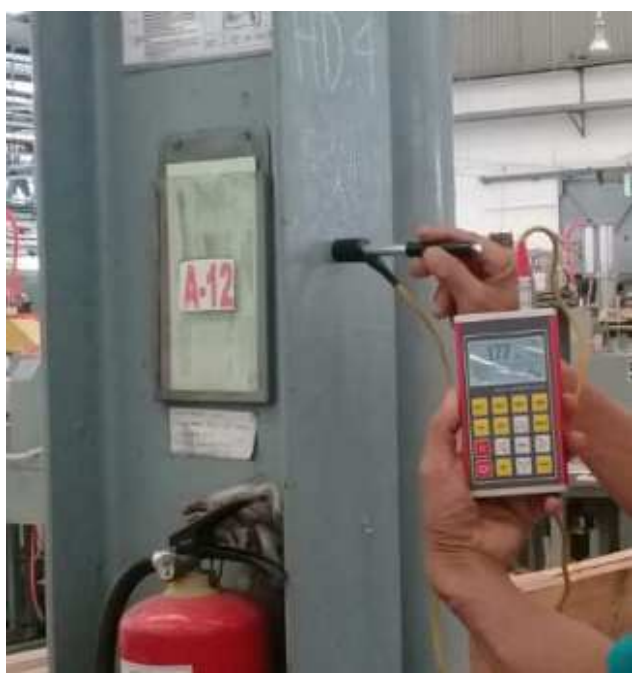

Gambar 4. Pengujian Brinell Hardness Test (Sumber: dok. PT Deltakoni)

\section{Hasil dan Analisa}

Bangunan yang diperiksa adalah bangunan existing yang telah dibangun sejak 1990, didesain berdasarkan peraturan desain yang berlaku saat itu. Karena bangunan sudah berumur lebih dari 25 tahun dan sudah berkali-kali mengalami pergantian peraturan, maka bangunan ini diperiksa ulang dengan peraturan yang terbaru. Layout denah lantai dasar, mezzanine, potongan portal bangunan terlihat pada Gambar 5-8.

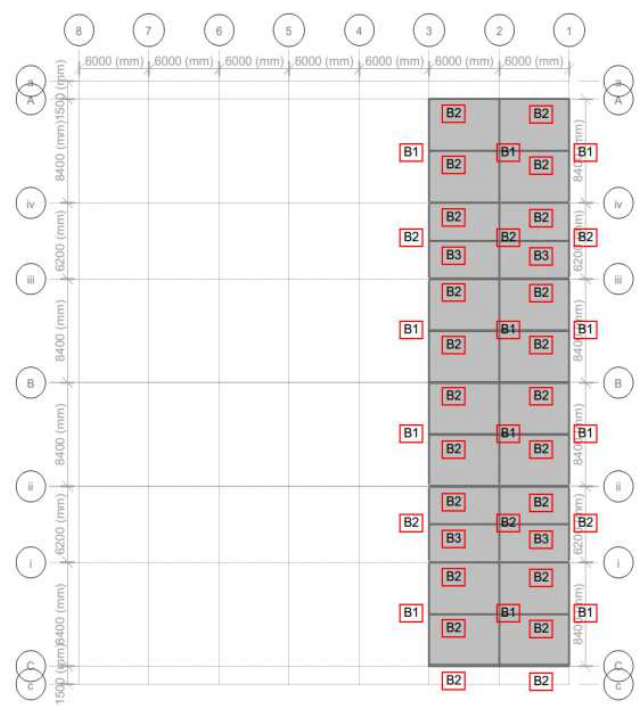

Gambar 5. Denah Struktur

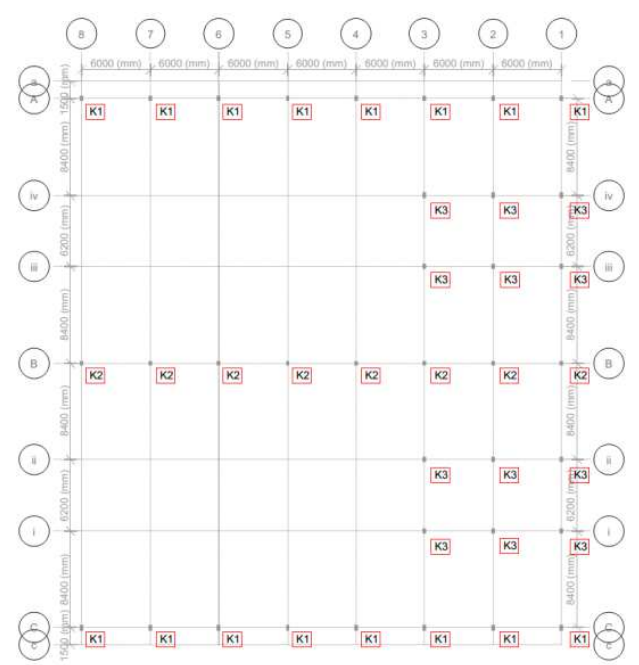

Gambar 6. Denah Lantai Mezzanine

Pengumpulan data lapangan aktual terpasang dilakukan sebelum analisis perhitungan dimulai. Pertamatama mempelajari sistem struktur yang terpasang dan melakukan pekerjaan penggambaran ulang struktur dengan cara investigasi visual dan mendata dan mengukur profil yang terpasang dilapangan dan kemudian membuat layout memverifikasi layout dari gambar as-built. Profil baja kemudian di ukur menggunakan meteran digital untuk memperoleh dimensi aktual untuk kemudian ditampilkan pada seperti Gambar 5 sampai dengan Gambar 8. Hasil pengumpulan data dapat dilihat pada Tabel 1 .

\section{Hasil UPV Test Mutu Beton Kolom Pedestal}

Pengumpulan properties dimulai dari mutu beton existing, beberapa titik kolom beton (pedestal) diuji dengan menggunakan alat UPV. Hasil pengujian dapat dilihat pada Tabel 2. Pengujian NDT yang dipakai adalah pengujian direct transmission dengan jarak transducer $20 \mathrm{~cm}$ menghasilkan gelombang suara ke dalam beton dan mengukur waktu yang diperlukan suara untuk melakukan perjalanan dari probe pemancar ke probe penerima melalui permukaan beton. 


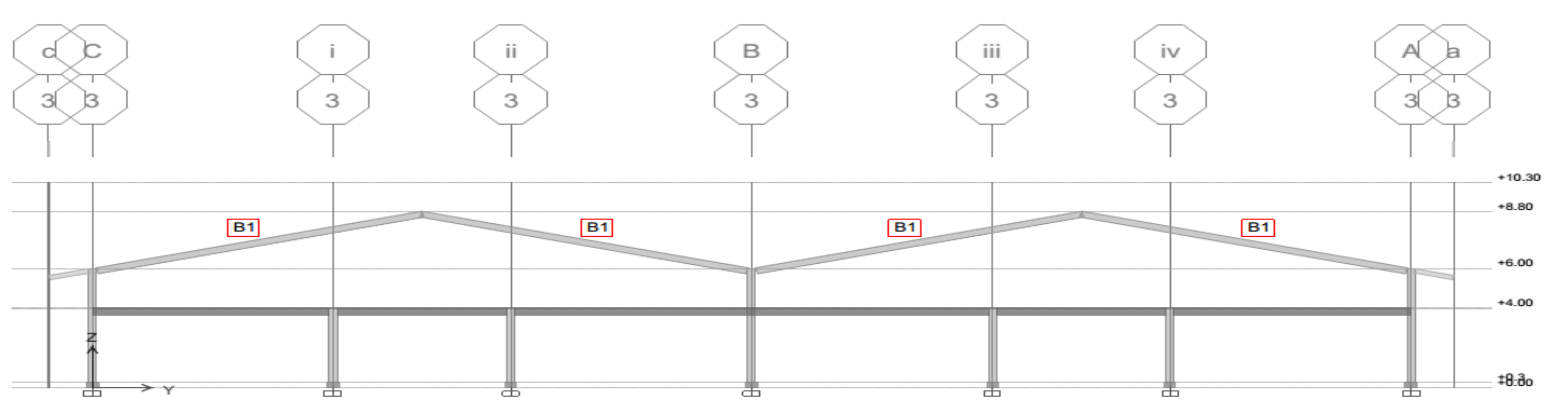

Gambar 7. Potongan Struktur As 1-3

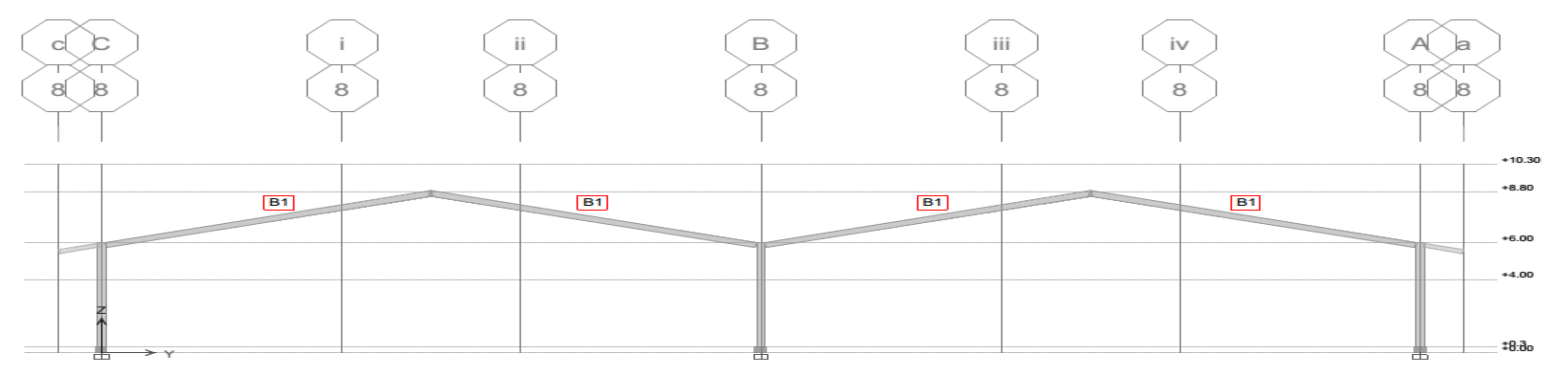

Gambar 8. Potongan Struktur As 4-8

Tabel 1. Hasil Investigasi Visual Profil Baja

\begin{tabular}{cccc}
\hline No & Kode & Ukuran Profil & Keterangan \\
\hline 1 & K1 & H 250X250X9X14 & Kolom \\
2 & K2 & H 300X300X10X15 & Kolom \\
3 & K3 & H 200X200X8X12 & Kolom \\
4 & B1 & WF 400X200X8X13 & Balok \& Rafter \\
5 & B2 & WF 350X175X7X11 & Balok \\
6 & B3 & WF 300X150X6.5X9 & Balok
\end{tabular}

Tabel 2. Hasil UPV Test

\begin{tabular}{ccc}
\hline Lokasi & Elemen Struktur & $\begin{array}{c}\text { Compressive } \\
\text { Strength } \\
\left(\mathrm{kg} / \mathrm{cm}^{2}\right)\end{array}$ \\
\hline 8C & Kolom Pedestal & 278.6 \\
8B & Kolom Pedestal & 321.8 \\
5B & Kolom Pedestal & 320.32 \\
18B & Kolom Pedestal & 321.62 \\
3i & Kolom Pedestal & 356.98 \\
1i & Kolom Pedestal & 392.7 \\
1B & Kolom Pedestal & 255.66 \\
1A & Kolom Pedestal & 298.64 \\
3A & Kolom Pedestal & 315.32 \\
6A & Kolom Pedestal & 293.82 \\
\hline
\end{tabular}

Tabel 2. Hasil UPV Test (Lanjutan)

\begin{tabular}{ccc}
\hline Lokasi & Elemen Struktur & $\begin{array}{c}\text { Compressive } \\
\text { Strength } \\
\left(\mathrm{kg} / \mathrm{cm}^{2}\right)\end{array}$ \\
\hline 8A & Kolom Pedestal & 304.64 \\
1iii & Kolom Pedestal & 281.26 \\
4C & Kolom Pedestal & 351.82 \\
7B & Kolom Pedestal & 324.92 \\
4A & Kolom Pedestal & 310.14 \\
2iv & Kolom Pedestal & 287.98 \\
5C & Kolom Pedestal & 332.66 \\
2C & Kolom Pedestal & 353.14 \\
7A & Kolom Pedestal & 358.84 \\
3iii & Kolom Pedestal & 343.24 \\
\hline & & \\
\hline
\end{tabular}

Dari hasil pengujian UPV sebanyak 20 sampel nilai rata rata mutu beton adalah $320.2 \mathrm{~kg} / \mathrm{cm}^{2}$. Dari hasil pengujian mutu beton terlihat mutu beton existing tidak mengalami banyak penurunan meskipun bangunan sudah berfungsi lebih dari 20 tahun dimana mutu beton rencana pada gambar as-built adalah 350 $\mathrm{kg} / \mathrm{cm}^{2}$.

\section{Hasil Brinell Hardness Test}

Pengumpulan data mutu baja dilakukan dengan menggunakan metode Brinell hardness test, hasil pengujian dapat dilihat pada Tabel 3. 
Tabel 3. Hasil Brinell Hardness Test Pada Kolom

\begin{tabular}{ccc} 
No & Element & $\begin{array}{c}\text { Tensile Strength } \\
\text { (MPa) }\end{array}$ \\
\hline 1 & Kolom & 145.34 \\
2 & Kolom & 263.92 \\
3 & Kolom & 199.88 \\
4 & Kolom & 153.86 \\
5 & Kolom & 315.12 \\
6 & Kolom & 154.52 \\
7 & Kolom & 192.06 \\
8 & Kolom & 168.72 \\
\hline
\end{tabular}

Tabel 4. Hasil Brinell Hardness Test Pada Rafter

\begin{tabular}{clc} 
No & Element & $\begin{array}{c}\text { Tensile Strength } \\
\text { (MPa) }\end{array}$ \\
\hline 9 & Rafter & 203.58 \\
10 & Rafter & 274.36 \\
11 & Rafter & 137.48 \\
12 & Rafter & 311.52 \\
13 & Rafter & 181.82 \\
14 & Rafter & 186.54 \\
15 & Rafter & 254.9 \\
16 & Rafter & 226.42
\end{tabular}

Dari hasil tes diperoleh nilai rata rata kolom baja adalah 199.2 MPa sedangkan pada bagian rafter adalah 222.1 $\mathrm{MPa}$.

\section{Analisis Struktur}

Data-data geometri properties dan mutu penampang yang sudah terkumpul dianalisa dengan menggunakan peraturan terbaru untuk struktur baja yaitu AISC 360-16, hasil Analisa dapat dilihat pada Tabel 5 dan Tabel 6.

Tabel 5. Momen Nominal Profil Berdasarkan AISC

\begin{tabular}{cccccc}
\multicolumn{7}{c}{ Tabel 5. Momen Nominal Profil Berdasarkan AISC } \\
\hline \multirow{2}{*}{ Code } & Steel Profile & Major & Minor & & \\
& & $\phi \mathrm{M}_{\mathrm{n}}$ & $\phi \mathrm{M}_{\mathrm{n}}$ & & \\
& & Tonm & Tonm & Ton & Ton \\
\hline B1 & WF 400X200X8X13 & 25.69 & 5.31 & 163.65 & 39.85 \\
B1 & WF 400X200X8X13 & 25.69 & 5.31 & 163.65 & 39.85 \\
B1 & WF 400X200X8X13 & 25.69 & 5.31 & 112.34 & 39.85 \\
B3 & WF 300X150X6.5X9 & 10.43 & 2.08 & 21.91 & 24.42 \\
B2 & WF 350X175X7X11 & 16.8 & 3.45 & 74.09 & 30.58 \\
B1 & WF 400X200X8X13 & 25.69 & 5.31 & 73.86 & 39.85 \\
B2 & WF 350X175X7X11 & 16.8 & 3.45 & 94.4 & 30.58 \\
\hline
\end{tabular}

Tabel 6. Perbandingan Rasio Profil Baja

\begin{tabular}{|c|c|c|c|c|c|c|}
\hline \multirow{3}{*}{ No } & \multirow{3}{*}{ Code } & \multirow{3}{*}{$\begin{array}{l}\text { Axial } \\
\text { Ton }\end{array}$} & \multicolumn{2}{|c|}{ Moment } & \multirow{3}{*}{$\begin{array}{c}\text { Shear } \\
\text { Ton }\end{array}$} & \multirow{3}{*}{ Total } \\
\hline & & & M33 & M22 & & \\
\hline & & & Ton.m & Ton.m & & \\
\hline 1 & B1 & 0.010 & 0.236 & 0.022 & 0.049 & 0.267 \\
\hline 2 & B1 & 0.010 & 0.320 & 0.020 & 0.051 & 0.350 \\
\hline 3 & B1 & 0.005 & 0.343 & 0.000 & 0.148 & 0.348 \\
\hline 4 & B3 & 0.002 & 0.810 & 0.000 & 0.264 & 0.812 \\
\hline 5 & B2 & 0.005 & 1.784 & 0.000 & 0.512 & 1.789 \\
\hline 6 & B1 & 0.001 & 0.320 & 0.000 & 0.190 & 0.321 \\
\hline 7 & B2 & 0.005 & 0.394 & 0.000 & 0.130 & 0.399 \\
\hline
\end{tabular}

Dari data diatas dapat diperoleh bahwa mutu baja tidak sesuai dengan standar di Indonesia yang mayoritas menggunakan kelas BJ-37. Hasil Brinell Hardness Test menunjukkan bahwa secara rata rata profil baja yang terpasang memiliki tegangan putus sebesar (fu) $199.2 \mathrm{MPa}$ pada kolom dan 222.1 MPa pada rafter, sedangkan kelas BJ37 seharusnya memiliki tegangan leleh minimum (fy) 240 MPa dan tegangan putus minimum (fu) $370 \mathrm{MPa}$. Maka dapat dikatakan bahwa mutu baja pada kondisi actual mengalami penurunan mutu.

Dari segi kapasitas penampang berdasarkan mutu baja hasil Brinell Hardness test, penampang profil masih memenuhi kriteria desain peraturan AISC 360-16. Karena bangunan ini merupakan bangunan yang sudah selesai dibangun dan sudah beroperasi, maka beban bangunan yang ada bisa di prediksi secara pasti. Oleh sebab itu metode analisis dapat dihitung dengan efektif untuk meninjau kapasitas struktur sesuai dengan peruntukan fungsi ruangan dan fungsi beban aktual. Data kapasitas struktur ini akan dijadikan acuan apakah dibutuhkan retrofit atau tidak. Pada Tabel 6 no 5 rasio baja mempunyai nilai $>1.00$ yang artinya beban yang terjadi melebihi kapasitas penampang dan perlu dilakukan retrofit.

Sedangkan hasil pengujian mutu beton terhadap kolom beton (pedestal) menunjukan penurunan kuat tekan beton sebesar 8\%, Data mutu beton aktual tersebut dianalisa ulang dengan peraturan $\mathrm{ACl}$ 318-14 dan diperoleh bahwa bangunan dengan umur bangunan yang sudah melebihi 20 tahun dan penurunan mutu beton hanya $8 \%$ masih memenuhi kriteria perencanaan struktur peraturan terbaru.

\section{Kesimpulan}

Pemeriksaan bangunan existing dengan metode NDT dapat dijadikan acuan dasar dan awal dalam mengevaluasi kapasitas bangunan existing secara cepat tanpa menggangu operasional gedung. Dengan demikian bangunan existing yang telah dievaluasi strukturnya dengan metode NDT dapat dinyatakan masih laik fungsi dan masih memenuhi kriteria desain peraturan terbaru. Metode pemeriksaan bangunan existing NDT dapat mendukung program pemerintah 
untuk penerbitan Sertifikat Laik Fungsi (SLF) dengan didukung analisis struktur oleh pengkaji struktur bangunan yang kompeten. Pemeriksaan NDT bersifat pemeriksaan dasar secara cepat, pemeriksaan tambahan secara DT misalnya coring beton, uji pembebanan dapat dilakukan untuk pemeriksaan yang lebih detail dan lengkap.

\section{Ucapan Terimakasih}

Ucapan terimakasih yang sebesar-besarnya kepada PT. Deltakoni selaku konsultan struktur proyek pemeriksaan bangunan Gudang di Cikupa Tangerang yang telah berbagi foto-foto dan gambar pelaksanaan kerja tes NDT diproyek tersebut dan ucapan terimakasih sebesar-besarnya kepada pemilik proyek gudang Cikupa Tangerang.

\section{Referensi}

ACl Committee 318. (2015) Building Code Requirements for Structural Concrete ( $\mathrm{ACl}$ 318-14): An ACl Standard: Commentary on Building Code Requirements for Structural Concrete (ACl 318R14), an ACl Report. American Concrete Institute.

AISC (2016), An American National Standard ANSI/AISC 360-16: Load Specification for Structural Steel Buildings", American Institute of Steel Construction

Dewobroto, W (2015a) SNI 1729:2015 dan Era Baru Perencanaan Baja Berbasis Komputer, Jurnal Teknik Sipil, Universitas Pelita Harapan.

Dewobroto, W (2015b) Struktur Baja - Perilaku, Analisis dan Desain - AISC 2010, Lumia Press.

Jayakumar, B. R. T., Thavasimuthu, M (2007) Practical Non-destructive Testing, Alpha Science International.

Sbartaï, Mehdi, Z., Breysse., Denys., Larget, A., Mathilde, B. (2007) Combining NDT techniques for improved evaluation of concrete properties" Cement and Concrete Composites, Volume 34, Issue 6, July, Pages 725-733. 